\title{
Indústria e serviços na Macrometrópole Paulista: para a caracterização produtiva de um amplo espaço econômico
}

\section{Palauras-chave \\ Região Metropolitana de São Paulo (RMSP), Macrometrópole Paulista, localização, espaço, serviços produtivos.}

\section{Classificação JEL O18, R11,} R12.

\section{Key words}

São Paulo's Metropolitan Region (SPMR), São Paulo's

Macrometropolis, location, space, productive services.

JEL Classification

018,R11

\section{Resumo}

$\mathrm{O}$ presente artigo intenta investigar as principais tendências locacionais presentes na economia paulista no pós 1985, com especial atenção para a formação de um espaço econômico mais amplo, formado pela Região Metropolitana de São Paulo (RMSP) e pelo seu entorno, também chamado de Macrometrópole Paulista. Argumentar-se-á que a sua característica básica é a articulação entre indústria e serviços produtivos, com a primeira tendendo a se tornar intensiva nas localidades adjacentes à metrópole paulista e os segundos, na própria capital. Vale destacar, entretanto, que a indústria permanece bastante concentrada na RMSP, de forma que a ascensão de segmentos de serviços não ocorreu em contexto de esvaziamento da indústria.

\section{Abstract}

This article aims to investigate Sao Paulo's post 1985 locational patterns, with special attention to the development of a wider economic territory, named Sao Paulo's Macrometropolis - constituted by Sao Paulo's Metropolitan Region (SPMR) and its adjoining regions. Its main characteristic is the existence of linkages amongst manufacture and productivity services, in such a pattern that the first tends to become intensive outside SPMR and the second, inside it. A further issue must be noted, however. The manufacture remains bighly concentrated in SPMR. In other words, at least in the case of SPMR, the development of productivity services should not be understood as a substitute for manufacture. 


\section{1_Introdução}

O objetivo do presente artigo $^{1}$ consiste na investigação da conformação produtiva de uma ampla região do Estado de São Paulo (ESP), composta da Região Metropolitana de São Paulo (RMSP) e de suas adjacências, comumente denominada de "Macrometrópole Paulista". Para tanto, será levado a cabo um exercício cujo ponto forte consiste em apon$\operatorname{tar}$ as tendências recentes referentes à formação desse amplo espaço econômico. Concretamente, o exercício operará a subdivisão da Região Macrometropolitana em localidades selecionadas a fim de, por um lado, examinar com um alto grau de acuidade a estrutura produtiva específica de cada uma dessas localidades e, por outro, identificar possíveis relações de complementaridade e/ou competição entre cada uma delas.

É importante mencionar que a discussão contida no presente artigo reporta-se ao campo da economia regional e serve-se das contribuições recentes dos debates da geografia econômica, da nova economia espacial e da sociologia econômica. Embora não procederei à discussão de cada um desses debates em separado, sua colaboração está inserida na discussão a seguir, a respeito dos pressupostos que possibilitam a consideração da região correspondente à $\mathrm{Ma}$ crometrópole Paulista como uma unidade econômica.

O primeiro pressuposto consiste na noção de que a dinâmica econômica da RMSP não pode mais ser considerada restrita aos limites político-administrativos dos municípios que a compõem, de modo que a sua investigação requer a ampliação de seu escopo, com a incorporação das regiões do seu entorno. A fim de validar esse pressuposto, vale evocar dois dos principais autores do desenvolvimento regional brasileiro recente.

Azzoni (1986) foi o primeiro autor a identificar o processo de espraiamento da indústria de transformação da RMSP rumo ao seu interior próximo, formando um campo aglomerativo ${ }^{2}$ de cerca de 150 quilômetros de raio a partir do centro da cidade de São Paulo, cuja dinâmica está diretamente relacionada à da hierarquia da desconcentração industrial da Região Metropolitana de São Paulo à formação da Macrometrópole Paulista.

2 O Campo Aglomerativo compreende, além da RMSP, as cidades de Campinas, São José dos Campos, Sorocaba, Santos e Jundiaí, entre outras. 
dinâmica da RMSP. Para o autor, é a articulação entre economias de urbanização não restritas à cidade central e o surgimento de deseconomias de aglomeração ${ }^{3}$ em tal cidade - expresso em custos locacionais crescentes com o tamanho urbano - que permitem às empresas industriais se localizarem dentro de uma dada região, relativamente ampla e, mesmo assim, gozarem das vantagens aglomerativas ${ }^{4}$ advindas da proximidade à cidade central. No caso específico, a localização na Região Macrometropolitana implica, ao mesmo tempo, fuga dos altos custos locacionais da RMSP e a obtenção de vantagens derivadas da proximidade à RMSP.

Diniz (1993, 1995 e 2002), ao discutir os impactos locacionais provindos das transformações na política macroe- conômica ${ }^{5}$, por um lado, e do processo de reestruturação produtiva ${ }^{6}$ por outro, fornece importante contribuição para o entendimento da dinâmica econômica recente da Macrometrópole Paulista. Esses dois fatores, em conjunto, tiveram o efeito de estancar o processo mais amplo de desconcentração da indústria de transformação brasileira ${ }^{7}$, em curso desde a década de 1970, e de apontar no sentido de um renovado movimento de reconcentração de determinadas atividades industriais que utilizam mais intensamente elementos como ciência, tecnologia e conhecimento.

Essas atividades contam com requisitos locacionais diferenciados, articulados com: (i) presença de centros de ensino, pesquisa e desenvolvimento; (ii) disponibilidade de mão de obra quali-
3 'Por 'deseconomias de aglomeração' entendia-se um conjunto de variáveis, entre as quais se destacam os maiores custos de transporte, de terrenos, de serviços e de infra-estrutura urbana, incluindose outras que provocam alteração na organização da produção e na sua produtividade, como ampliação do poder sindical da classe trabalhadora, questões ambientais, deterioração nas condições de vida nos grandes centros urbanos, queda na produtividade do trabalho etc." (Negri, 1996, p. 15).

\section{Destaque para o tamanho} do mercado consumidor, acesso à oferta de serviços típicos de uma metrópole como São Paulo, à disponibilidade de mão de obra diversificada e qualificada etc.

5 Mudança do papel do Estado - principalmente quanto ao fim da política industrial e regional -, rápido processo de abertura comercial e de desregulamentação econômica e de privatizações.
6 Rápido processo de modernização tecnológica das empresas, caracterizado pelo aumento da produtividade sem ser acompanhado pelo aumento do nível de emprego, e que teve origem na introdução de novas formas de organização da produção. Para mais informações, ver Sabóia (1997), Araújo (2001), Castro (2001) e Kupfer e Rocha (2004).
A esse respeito, além dos já citados trabalhos de Diniz (1993, 1995 e 2002) e de Azzoni (1986), ver também Pacheco (1998 e 1999), Cano (1998) e Caiado (2002). 
ficada e diversificada, infraestrutura de comunicação e setor serviços urbanos modernos e especializados; (iii) relações econômicas integradas geograficamente; e (iv) facilidade para contatos face a face e para a inovação. ${ }^{8}$ Tais requisitos, também chamados de "modernos", tendem a se concentrar em regiões com grande aglomeração urbana ao mesmo tempo em que o desenvolvimento e o crescimento de atividades intensivas em ciência, tecnologia e conhecimento apontam para o reforço do potencial aglomerativo dessas regiões, conformando um processo de causação circular, no qual economias de aglomeração e rendimentos crescentes reforçam-se mutuamente. ${ }^{9}$

No caso brasileiro, caracterizado por agudas desigualdades regionais, a emergência dos fatores locacionais modernos, potencializados pelos já tradicionais e também concentrados tamanho do mercado consumidor e infraestrutura de transportes, privilegiou, determinantemente, a Região Macrometropolitana.

O segundo pressuposto, diretamente associado ao anterior, parte da identificação da emergência de um dinâmico setor de serviços produtivos ${ }^{10}-$ especialmente daqueles de caráter mais moderno - na RMSP, ao longo dos últimos vinte anos, e que está funcional- mente ligado à competitividade das empresas - industriais ou não - localizadas na Macrometrópole.

Esse movimento está associado, por um lado, a um processo mais amplo, que diz respeito às novas formas de produção de bens e serviços na economia capitalista contemporânea, e que se caracteriza pela crescente homogeneização entre os setores industrial e de serviços quanto a elementos próprios de seu padrão concorrencial, tecnológico e organizacional (Bernardes et al., 2005). Em subdivididos em: (i) serviços produtivos: atividades intermediárias das empresas de apoio à produção, como serviços financeiros, jurídicos, de informática, de pesquisa, de engenharia, de consultoria, de propaganda e marketing, de seguro e de auditoria; (ii) serviços distributivos: atividades efetuadas após o término do processo produtivo, como transporte, armazenamento e comunicação; (iii) serviços sociais: atividades realizadas para a sociedade, como saúde e educação; e (iv) serviços pessoais: atividades realizadas para atender à demanda individual, como hotelaria, restaurante e limpeza (Comin, 2003, p. 58-59). 
que pesem importantes diferenças no que toca à produção de bens tangíveis ou intangíveis e à velocidade de incorporação de novos padrões organizacionais e tecnológicos, pode-se afirmar que a indústria assumiu características comumente associadas aos serviços, como a crescente dependência de mão de obra qualificada, atendimento customizado, atuação em nichos específicos de mercado e dependência de serviços especializados, enquanto o setor de serviços como um todo, mas com especial destaque para o conjunto do que aqui se chama de "serviços produtivos", assimilou características marcadamente industriais, $\mathrm{CO}^{-}$ mo a predominância da grande empresa, a importância de economias de escala e os altos investimentos de capital físico (Boden e Miles, 2000).

Por outro lado, o movimento de emergência do dinâmico setor de serviços produtivos associou-se também ao processo de reestruturação produtiva brasileiro, próprio da década de 1990 e que foi sentido de maneira mais intensa justamente em São Paulo, região cujo parque produtivo é o mais denso e diversificado do País. Caracterizou-se pela transferência de atividades não ligadas ao centro da produção e das ocupações a elas correspondentes, para o setor de serviços, bem como pela criação de um ambiente propício ao surgimento de novos serviços já fora da esfera industrial (Comin e Amitrano, 2003; Bessa, 2004; Torres-Freire, 2006). Entre as primeiras, destacam-se tanto atividades rotineiras, como alimentação, segurança, vigilância e limpeza, quanto atividades que envolvem a utilização intensiva de conhecimento e mão de obra especializada, como publicidade, pesquisa e desenvolvimento, serviços jurídicos e algumas atividades de informática. Entre as demais, bons exemplos são certos nichos das telecomunicações e da informática e uma miríade de consultorias especializadas.

Uma vez fora da indústria, as atividades aqui denominadas de "serviços produtivos" adquiriram renovada dinâmica. A indústria deixa de ser o único cliente para tornar-se um cliente entre outros, muitas vezes menos importante que outras atividades de serviços (Torres-Freire, 2006). Nesse sentido, os serviços produtivos devem ser considerados como um conjunto de atividades transversais a todos os setores da economia, inclusive aos próprios serviços. Do ponto de vista da indústria, entretanto, em razão de a RMSP ter-se tornado um importante polo ofertante de serviços especializados constitui-se um fator 
determinante para a manutenção e ampliação da sua competitividade.

O terceiro pressuposto, por fim, tem a ver com o fato de as cidades, ou melhor, as metrópoles, constituírem-se como espaços nos quais a atividade de diversificação produtiva - criação de outras atividades com base em atividades preexistentes - ocorre (Jacobs, 1970 e 1984) ${ }^{11}$.É fundamentalmente por meio dessa atividade, expressa no sistemático incremento de novos bens e serviços, a partir de bens e serviços já existentes, que o desenvolvimento e o dinamismo econômico são gerados.

Do ponto de vista da trajetória do produto, ou mesmo do setor, apontam Duranton e Puga (2000 e 2001), o ambiente metropolitano e, portanto, toda a sua diversificação, é fundamental para a fase inicial do produto e/ou setor, visto que é nela que as atividades mais intensivas em pesquisa, desenvolvimento e inovação estão concentradas. Já as fases maduras, por sua vez, mais relacionadas à produção em massa para um vasto mercado e mais dependentes da eficiência produtiva, tendem a concentrar suas atividades em cidades menores, porém, especializadas, nas quais os custos sejam reduzidos.
Dessa forma, o espaço metropolitano deve ser considerado como qualitativamente diferenciado do ponto de vista produtivo, seja porque concentra o processo de incorporação e de criação de outros bens e serviços - ou, para usar um termo mais em voga, é local produtor de inovações -, seja porque concentra as atividades mais dinâmicas da economia. ${ }^{12}$ Não admira, portanto, que os serviços especializados de apoio à produção, que saíram do seio do setor industrial ou mesmo aqueles que foram criados nesse novo ambiente, tenham as Regiões Metropolitanas como seu principal sítio de produção. ${ }^{13}$

\section{O exercício: para uma investigação da Macrometrópole Paulista}

Com esses três pressupostos explicitados, passo agora para uma sucinta justificativa da base de dados e dos indicadores que utilizo para a apresentação da classificação geográfica que sustenta o exercício e para a discussão do uso de medidas locacionais: o Quociente Locacional (QL), mais especificamente, como forma de auxiliar na caracterização produtiva do ESP, da Região Macrometropolitana e de suas localidades.

A base de dados utilizada é a Relação Anual de Informações Sociais
${ }^{11}$ A atividade de diversificação produtiva é pensada em oposição à de especialização produtiva - modo de organizar a produção com o objetivo de aumentar a sua eficiência, ou seja, produzir mais do mesmo.

12 O termo "inovação", aqui, deve ser entendido de forma bastante ampla: utilização comercial de conhecimento novo e/ou uma nova utilização ou combinação de conhecimento já existente (Arbix, 2007).

13 Valendo-se de outra perspectiva, autores como Sassen (1998 e 2001) e Castells (1999) também apontam para o fato de as grandes cidades terem se tornado locais produtores de serviços especializados. 
(Rais). ${ }^{14}$ Embora possua desvantagens, como problemas de coleta e processamento de dados ${ }^{15}$ e o fato de não se constituir como a base mais indicada para investigações acerca da dinâmica produtiva - já que a utilização de dados de emprego formal para o estudo da localização da atividade econômica, como é sabido, pode encobrir diferencial regional e setorial de produtividade -, a Rais dispõe de vantagens que superam, em muito, tais problemas. Grande destaque para a sua extensa série histórica, que permite a captação de processos de médio e longo prazos, e para a possibilidade de ampla desagregação geográfica e setorial, permitindo a utilização de classifi-

\footnotetext{
14 A Rais é uma importante fonte de dados sobre o mercado de trabalho formal no Brasil, tendo sido instituída pelo Ministério do Trabalho (atualmente, Ministério do Trabalho e Emprego - MTE) em 1975. Ela permite análises em série histórica a partir de 1985, e sua declaração é preenchida anualmente por todos os estabelecimentos inscritos no Cadastro Nacional de Pessoas Jurídicas (CNPJ).

15 Suzigan et al. (2003) aponta que a autoclassificação, método
}

cação de municípios e de atividades econômicas igualmente desagregadas. Além do mais, conforme apontado por Pacheco (1999), o diferencial de produtividade não foi, nas décadas de 1980 e 1990, tão exorbitante a ponto de inviabilizar uma análise tal qual a aqui feita.

Ainda que a Rais conte também com a possibilidade de utilização de indicadores referentes às unidades produtivas, serão apresentados apenas indicadores de mão de obra. Em que pese a necessidade de concisão, própria de um artigo científico, a principal justificativa relaciona-se ao julgamento que tais indicadores são suficientes para a identificação das principais características e tendências próprias do fenômeno abordado pelo presente artigo. De uma forma ou de outra, mais do que estabelecer conclusões finais e fechadas sobre a dinâmica econômica da Macrometrópole Paulista, intenta-se levantar elementos para a discussão de um tema bastante atual e relevante.

Por fim, indicadores de valor agregado ou de transformação industrial não foram incorporados pelo fato de as bases de dados disponíveis, como os Censos Industriais, até a década de 1980, a Pesquisa Industrial Anual (PIA), a partir dos anos 1990, ou a Pesquisa da Ativi- 
dade Econômica Paulista (PAEP), para 1996 e $2001,{ }^{16}$ não apresentarem cobertura para a totalidade do período abordado e/ou por não contarem, graças aos seus respectivos desenhos amostrais, com possibilidades de desagregação geográfica e setorial.

Com o objetivo de investigar a composição produtiva da Macrometrópole Paulista, bem como a possível existência de relações de complementaridade e/ou competição entre suas determinadas localidades, o ESP foi dividido em sete localidades: RMSP, Região Metropolitana de Campinas (RMCam), Resto da Região Administrativa de Campinas (Resto da RAC), Região Metropolitana da Baixada Santista (RMBS), Região Administrativa de São José dos Campos (RASJC), Região Administrativa de Sorocaba (RASor) e Demais Regiões Administrativas do ESP (Outras RAs).

Essa forma de agregar os municípios do ESP encerra, por um lado, a necessidade de separar o ESP em três regiões - RMSP, Campo Aglomerativo da RMSP e Resto do ESP, cada qual possuidora de uma dinâmica econômica e locacional particular no passado recente; e, por outro, a necessidade de se dividir a Macrometrópole Paulista em localidades selecionadas - RMSP, RMCam, Res- to da RAC, RMBS, RASJC e RASor a fim de investigar a dinâmica produtiva própria de cada uma delas, bem como a qualidade das suas respectivas inserções na Macrometrópole.

A separação da Região Administrativa de Campinas em RMCam e em Resto da RAC intenta captar as diferenças relativas à estrutura produtiva entre esses dois espaços do Estado. Conforme foi argumentado, os espaços metropolitanos constituem-se como espaços qualitativamente diferenciados para a localização da atividade econômica, de modo que é esperado que exista significativa diferença entre a estrutura produtiva dessas duas localidades. ${ }^{17}$

Para melhor caracterização da estrutura produtiva das localidades em questão, além da participação relativa de cada setor industrial e de cada ramo de atividade econômica, será utilizado o quociente locacional (QL), que consiste em uma medida locacional, cujo objetivo é auxiliar na identificação de especialização produtiva de uma dada região em determinado setor/ramo de atividade (Haddad, 1989, p. 233). A utilização do QL, ao lado da participação relativa, permite minimizar problemas relativos à sobre-estimação/subestimação de setores/ramos mais ou menos intensivos em
16 Para um teste de consistência dos indicadores construídos com base na manipulação da Rais tendo dados de número de empresas, mão de obra, valor adicionado, rendimento líquido e produtividade da Paep 2001 como referência, ver Abdal (2008).

${ }^{17}$ É importante lembrar que a RMCam, além de possuir mercado qualificado e diversificado de trabalho e infraestrutura adequada para as atividades industriais mais modernas e dinâmicas, nela se localizam importantes universidades - como a Unicamp e a Puccamp - e instituições de pesquisa como o Centro de Pesquisa e Desenvolvimento (CPqD), a Companhia de Desenvolvimento Tecnológico (Codetec) e o Laboratório

Nacional de Luz

Sincroton (LNLS). 
18 Sua fórmula é dada por: $Q L=E_{j}^{a} / E_{E S P}^{a} / E_{j}^{a t v} / E_{E S P}^{a t v}$; onde se lê:

$E_{j}^{a}$ : emprego da atividade específica na região específica; $E_{E S P}^{a}$ : emprego da atividade específica no ESP;

$E_{j}^{a t v}$ : emprego na região específica;

$E_{E S P}^{a t v}$ : emprego no ESP.

19 Por exemplo, outras medidas locacionais, como o coeficiente de localização (CL), o coeficiente de especialização (CE), o coeficiente de reestruturação (CT) etc. ou mesmo metodologias mais sofisticadas, como a análise de shift-share. trabalho, possibilitando a identificação das tendências mais relevantes do período analisado.

O uso do QL é tradicional na literatura sobre desenvolvimento regional. Por meio dele, é possível comparar duas estruturas setoriais-espaciais, a fim de ajudar na identificação de especializações produtivas - ou, pelo menos, de concentrações setoriais desproporcionais. Para tanto, compara a participação de uma região em um setor específico com a participação do mesmo setor no total da economia. Se o valor do QL desse setor na região em questão for maior que um, significa que a importância do setor nessa região perante a economia como um todo é maior do que a importância do conjunto dos setores dessa região ante essa economia. ${ }^{18}$

Crocco et al. (2006, p. 220) apontam que, embora muito úteis, os resultados do QL devem ser interpretados com certa cautela. Primeiro, a interpretação de seu resultado deve considerar as características da economia de referência no caso, o ESP. Segundo, em economias com elevado grau de disparidade regional, como o Brasil, pode ocorrer de o QL ser acima de um, sem que isso represente uma especialização produtiva, mas apenas uma diferenciação produtiva, de- rivada das diferentes características das regiões. Terceiro, em pequenas regiões, com número diminuto de ocupados e estrutura produtiva pouco diversificada, o QL tende a sobrevalorizar o peso de um ou de alguns setores. Em regiões muito grandes, ao contrário, com alto número de empregados e estrutura produtiva muito diversificada, o QL tende a subvalorizar o peso de alguns setores, mesmo que sejam relevantes para a economia como um todo.

$\mathrm{O}$ potencial perigo de viés associado ao QL pode, entretanto, ser minimizado. Primeiro, a real consideração das características específicas do ESP, bem como a consideração de literatura específica e de dados complementares ${ }^{19}$ ao QL, podem evitar uma utilização superficial do índice. No caso do presente, entretanto, os resultados do QL serão balizados apenas com dados setoriais de participação relativa, proporcionando um quadro compatível com o objetivo subjacente de identificação de tendências. Segundo, o ESP é um espaço muito mais homogêneo do que o Brasil, e a consideração apenas do setor industrial e a utilização de uma classificação do setor de serviços bastante agregada contribuem para tornar esse espaço ainda mais homogêneo. Por último, o problema da 
sub ou sobre-estimação de determinados setores se constitui como um problema um pouco mais complexo. Mas, com exceção da RMSP, as demais localidades são de tamanho relativamente próximo, o que minimiza a questão da sobrevalorização de setores.

O problema da subvalorização de certos setores, porém, atinge em cheio a RMSP, o que pode ser observado na comparação da distribuição setorial da indústria por localidade do ESP. Dessa forma, comparações diretas a partir do QL de um mesmo setor entre as diferentes localidades não são recomendáveis. Por outro lado, não há problema nenhum em realizar tais comparações entre diferentes setores de uma mesma localidade.

\section{As sete localidades selecionadas perante o Estado de São Paulo}

Começarei por discutir a trajetória de cada localidade ante o ESP, ao longo do período $1985-2005 .{ }^{20}$ O Gráfico 1 possibilita a observação da distribuição dos ocupados na indústria, por localidade selecionada do ESP.

O primeiro fato que chama a atenção é a perda de importância da RMSP em relação a todas as demais localidades, com exceção da RMBS. Assim, mes- mo mantendo participação significativa, a RMSP chega ao fim do período com participação no emprego industrial do Estado inferior a 50\%.

Em relação às localidades específicas do Campo Aglomerativo da RMSP, destaca-se o crescimento expressivo da RMCam, do Resto da RAC e da RASor, as quais experimentaram crescimento relativo e absoluto do seu nível de emprego. A RASJC, apesar de ter tido certo crescimento relativo, apresenta, em 2005, uma população ocupada na indústria inferior à de 1985. Por fim, a RMBS parece viver um movimento bastante distinto das demais localidades da Macrometrópole, tendo tido expressiva perda absoluta e relativa do seu nível de emprego industrial, principalmente a partir de 1999.

Quanto ao desempenho das Outras RAs do ESP, convém destacar o grande crescimento registrado. Em termos absolutos, há aumento de quase $30 \%$ no número de postos de trabalho industriais oferecidos entre 1985 e 2005, enquanto em termos relativos atinge, em 2005, um peso próximo à casa dos $20 \%$. Configura-se, assim, como a segunda maior localidade do ESP, atrás apenas da RMSP, e como a localidade que experimentou maior crescimento no período.

\footnotetext{
${ }^{20}$ Infelizmente, não foi possível construir, com base na Rais, todos os dados para o período 1985-2005. Os dados relativos ao setor de serviços, mais adiante, referem-se ao período 1995-2005.
} 
Gráfico 1_ Distribuição dos ocupados na indústria por localidade selecionada do ESP (1985-2005)

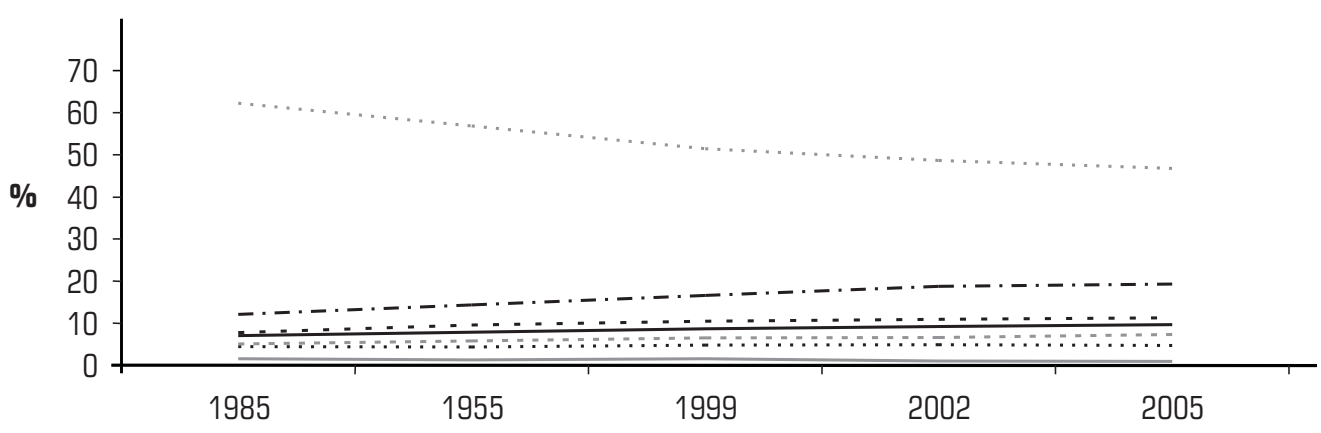

Ano

$\begin{array}{lllll} & \text { RMCam } & -\cdots & \text { RASor } & \text { RMBS } \\ -\cdots- & \text { Resto RAC } & -\ldots & \text { RMSP } \\ \ldots . . & \text { RASJC } & & & \end{array}$

\begin{tabular}{|c|c|c|c|c|c|c|c|c|c|c|}
\hline \multirow{2}{*}{ Localidade } & \multicolumn{2}{|c|}{1985} & \multicolumn{2}{|c|}{1995} & \multicolumn{2}{|c|}{1999} & \multicolumn{2}{|c|}{2002} & \multicolumn{2}{|c|}{2005} \\
\hline & Abs. & $\%$ & Abs. & $\%$ & Abs. & $\%$ & Abs. & $\%$ & Abs. & $\%$ \\
\hline RMCam & 175.580 & 7,0 & 164.640 & 7,9 & 152.500 & 8,7 & 172.620 & 9,2 & 211.700 & 9,7 \\
\hline Resto RAC & 193.580 & 7,7 & 200.940 & 9,6 & 185.000 & 10,5 & 205.560 & 10,9 & 247.220 & 11,3 \\
\hline RASJC & 110.680 & 4,4 & 90.380 & 4,3 & 83.080 & 4,7 & 92.140 & 4,9 & 102.540 & 4,7 \\
\hline RASor & 126.560 & 5,1 & 120.260 & 5,7 & 114.180 & 6,5 & 124.840 & 6,6 & 158.840 & 7,3 \\
\hline Outras RAs & 302.580 & 12,1 & 300.580 & 14,4 & 291.240 & 16,6 & 352.160 & 18,7 & 420.620 & 19,3 \\
\hline RMBS & 37.440 & 1,5 & 26.140 & 1,2 & 26.620 & 1,5 & 18.500 & 1,0 & 21.900 & 1,0 \\
\hline RMSP & 1.557 .920 & 62,2 & 1.190 .580 & 56,9 & 901.780 & 51,4 & 912.500 & 48,6 & 1.021 .000 & 46,8 \\
\hline Total & 2.504 .620 & 100,0 & 2093.520 & 100,0 & 1.754 .400 & 100,0 & 1.878 .320 & 100,0 & 2.183 .820 & 100,0 \\
\hline
\end{tabular}

Fonte: RAIS/MTE. Elaboração própria. 
Na Tabela 1, é possível observar a distribuição dos ocupados nos quatro ramos de serviços por localidade selecionada do ESP. Deve-se atentar, primeiro, para o fato de que, ao final do período, pelo menos do ponto de vista do emprego, todos os quatro ramos permaneceram relativamente mais concentrados na RMSP que a indústria, ${ }^{21}$ o que não se verifica em 1995, quando só os serviços produtivos e os sociais encontravam-se com participação na RMSP maior que a indústria. Essa observação geral indica que o movimento de perda de peso relativo da RMSP foi mais intenso na indústria do que em qualquer um dos ramos de serviços.

Também é necessário chamar a atenção para a performance diferencial dos serviços produtivos em relação aos demais ramos de serviços, seja porque é o ramo de serviços mais concentrado na RMSP, seja porque, ao contrário dos demais, sua participação na região não diminuiu ao longo do tempo, e, sim, aumentou - tendo chegado, em 2005, a concentrar $71 \%$ dos empregos. Tal evidência sugere que esse conjunto de serviços possui certas qualidades distintas daquelas próprias dos demais conjuntos de serviços.
Já no que concerne às Outras RAs do ESP, ressalta-se apenas que, para os serviços distributivos, sociais e pessoais, elas tenderam a absorver $\mathrm{O}$ recuo da RMSP de forma relativamente proporcional. Para os serviços produtivos, a única localidade - com exceção da RMSP - que não experimentou perda de peso relativo foi a RMCam, o que sugere que essa região pode vir a firmar-se como um polo alternativo e/ou complementar de serviços produtivos à RMSP, ao menos em algumas atividades específicas.

\section{A Região Metropolitana de São Paulo}

Embora nos últimos vinte anos a indústria da RMSP tenha diminuído seu peso relativo no Estado para "apenas" 46,8\% dos empregados industriais, essa é a localidade que possui o parque industrial mais denso e diversificado - esse tema será discutido a seguir, a partir da Tabela 3. Por hora, convém voltar a atenção para a Tabela 2, na qual é possível observar a evolução dos ocupados e os QLs na RMSP para todos os ramos de atividade econômica.

\footnotetext{
21 Os ramos de serviços apresentaram, em 2005, participação relativa na RMSP acima da casa dos 50\%, enquanto a da indústria caiu para "apenas" 46,8\%.
} 
Tabela 1_ Distribuição dos ocupados nos serviços distributivos, produtivos, sociais e pessoais segundo localidade selecionada do ESP (1995-2005)

\begin{tabular}{|c|c|c|c|c|c|c|c|c|c|}
\hline \multirow{2}{*}{\multicolumn{2}{|c|}{ Localidade }} & \multicolumn{2}{|c|}{1995} & \multicolumn{2}{|c|}{1999} & \multicolumn{2}{|c|}{2002} & \multicolumn{2}{|c|}{2005} \\
\hline & & Abs. & $\%$ & Abs. & $\%$ & Abs. & $\%$ & Abs. & $\%$ \\
\hline \multirow{8}{*}{ 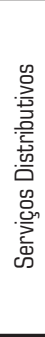 } & RMCam & 85.980 & 6,0 & 107.200 & 7,0 & 132.820 & 7,3 & 176.080 & 7,8 \\
\hline & RAC & 94.160 & 6,6 & 111.520 & 7,3 & 137.040 & 7,5 & 182.880 & 8,1 \\
\hline & RASJ & 56.860 & 4.0 & 66.120 & 4,3 & 79.840 & 4,4 & 95.580 & 4,2 \\
\hline & RASor & 65.120 & 4,6 & 73.960 & 4,8 & 93.880 & 5,1 & 114.300 & 5,1 \\
\hline & Outras RAs & 227.600 & 16,0 & 259.240 & 17,0 & 315.320 & 17,2 & 398.720 & 17,7 \\
\hline & RMBS & 64.340 & 4,5 & 62.600 & 4,1 & 72.560 & 4,0 & 90.980 & 4,0 \\
\hline & RMSP & 830.880 & 58,3 & 846.860 & 55,4 & 997.780 & 54,5 & 1.196 .100 & 53,1 \\
\hline & ESP & 1.424 .940 & 100,0 & 1.527 .500 & 100,0 & 1.829 .240 & 100,0 & 2.254 .640 & 100,0 \\
\hline \multirow{8}{*}{ 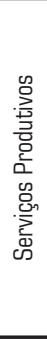 } & RMCam & 60.420 & 4,9 & 76.360 & 5,3 & 90.100 & 5,6 & 108.220 & 5,9 \\
\hline & RAC & 68.040 & 5,5 & 70.320 & 4,9 & 82.560 & 5,2 & 91,860 & 5,0 \\
\hline & RASJ & 32.980 & 2,7 & 44.240 & 3,1 & 56.480 & 3,5 & 62,160 & 3,4 \\
\hline & RASor & 50.860 & 4,1 & 68.580 & 4,8 & 66.860 & 4.2 & 55.040 & 3,0 \\
\hline & Outras RAs & 126.680 & 10,2 & 123.860 & 8.7 & 149.360 & 9,4 & 151.860 & 8,3 \\
\hline & RMBS & 49.140 & 4,0 & 51.720 & 3,6 & 52.140 & 3,3 & 60.120 & 3,3 \\
\hline & RMSP & 855.260 & 68,8 & 995.220 & 69.6 & 1.099 .340 & 68.8 & 1.294 .720 & 71,0 \\
\hline & ESP & 1.243 .380 & 100,0 & 1.430 .300 & 100,0 & 1.596 .840 & 100,0 & 1.823 .980 & 100,0 \\
\hline \multirow{8}{*}{ 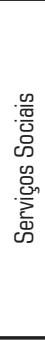 } & RMCam & 37.420 & 6,8 & 45.120 & 7,7 & 49.860 & 7,6 & 53.880 & 7,1 \\
\hline & RAC & 38.420 & 7,0 & 44.740 & 7,6 & 47.720 & 7,2 & 54.860 & 7,3 \\
\hline & RASJ & 24.920 & 4,5 & 23.980 & 4,1 & 28.280 & 4,3 & 33.020 & 4,4 \\
\hline & RASor & 23.300 & 4,2 & 24.580 & 4,2 & 23.920 & 3,6 & 29.220 & 3,9 \\
\hline & Outras RAs & 97.960 & 17,8 & 106.980 & 18,2 & 124.380 & 18,8 & 136.320 & 18,1 \\
\hline & RMBS & 19.260 & 3,5 & 22.320 & 3,8 & 23.480 & 3,6 & 23.980 & 3,2 \\
\hline & RMSP & 307.700 & 56,0 & 318.700 & 54,3 & 362.300 & 54,9 & 423.860 & 56,1 \\
\hline & ESP & 548.980 & 100,0 & 586.420 & 100,0 & 659.940 & 100,0 & 755.140 & 100,0 \\
\hline \multirow{8}{*}{ 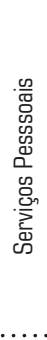 } & RMCam & 17.300 & 5,9 & 22.880 & 7,4 & 27.140 & 7,6 & 32.660 & 7,7 \\
\hline & RAC & 17.640 & 6,0 & 19.760 & 6,4 & 21.760 & 6,1 & 27.220 & 6,4 \\
\hline & RASJ & 13.260 & 4,5 & 16.720 & 5,4 & 21.160 & 5,9 & 24.460 & 5,8 \\
\hline & RASor & 12.600 & 4,3 & 12,100 & 3,9 & 16.000 & 4,5 & 22,640 & 5,3 \\
\hline & Outras RAs & 32.280 & 11,0 & 39,840 & 12,9 & 46.300 & 13,0 & 57,000 & 13,4 \\
\hline & RMBS & 12.340 & 4,2 & 13,420 & 4,3 & 17.780 & 4,2 & 18,120 & 4,3 \\
\hline & RMSP & 187.520 & 64,0 & 185.120 & 59,7 & 208.960 & 58,7 & 241.900 & 57,1 \\
\hline & ESP & $\begin{array}{r}292.940 \\
\ldots \ldots \ldots\end{array}$ & $\begin{array}{l}100,0 \\
\ldots . . .\end{array}$ & $\begin{array}{r}309.840 \\
\ldots \ldots \ldots\end{array}$ & $\begin{array}{l}100,0 \\
. . . . .\end{array}$ & $\begin{array}{r}356.100 \\
\ldots \ldots \ldots\end{array}$ & $\begin{array}{l}100,0 \\
\ldots \ldots \ldots\end{array}$ & $\begin{array}{l}424.000 \\
\ldots \ldots \ldots\end{array}$ & $\begin{array}{l}100,0 \\
\ldots . \cdots\end{array}$ \\
\hline
\end{tabular}

FONTE: Rais/MTE. Elaboracão própria. 
Tabela 2_Distribuição dos ocupados e QLs na RMSP por ramo de atividade econômica (1995 e 2005)

\begin{tabular}{|c|c|c|c|c|c|c|}
\hline \multirow{2}{*}{ Atividade } & \multicolumn{3}{|c|}{1995} & \multicolumn{3}{|c|}{2005} \\
\hline & Abs. & $\%$ & QL & Abs. & $\%$ & QL \\
\hline Indústria & 1.176 .600 & 26,0 & 0,96 & 982.040 & 18,1 & 0,83 \\
\hline Construção civil & 224.100 & 5,0 & 1.09 & 191.640 & 3,5 & 1,04 \\
\hline S. distributivos & 830.880 & 18,4 & 0,99 & 1.196 .100 & 22,0 & 0,95 \\
\hline S. produtivos & 855.260 & 18,9 & 1,16 & 1.294 .720 & 23,8 & 1,28 \\
\hline S. sociais & 307.700 & 6,8 & 0,95 & 423.860 & 7,8 & 1,01 \\
\hline S. pessoais & 187.520 & 4,2 & 1,08 & 241.900 & 4,5 & 1.03 \\
\hline Governo & 853.860 & 18,9 & 1,15 & 984.760 & 18,1 & 1,20 \\
\hline Ativ. primárias & 23.640 & 0,5 & 0,12 & 17.580 & 0,3 & 0,09 \\
\hline Outras ativ. & 58.740 & 1,3 & 0,82 & 97.520 & 1,8 & 0,81 \\
\hline Total & 4.518 .300 & 100,0 & 1,00 & 5.430 .120 & 100,0 & 1,00 \\
\hline
\end{tabular}

Fonte: Rais/MTE. Elaboração própria.

Tabela 3_ Distribuição dos ocupados e QLs na RMSP por setor industrial (1985 e 2005)

\begin{tabular}{|c|c|c|c|c|c|c|}
\hline \multirow{2}{*}{ Setor industrial } & \multicolumn{3}{|c|}{1985} & \multicolumn{3}{|c|}{2005} \\
\hline & Abs. & $\%$ & QL & Abs. & $\%$ & $\mathbf{Q L}$ \\
\hline Alimentos e bebidas & 81.680 & 5,2 & 0,51 & 106.140 & 10,4 & 0,64 \\
\hline Borracha, fumo e couro & 123.040 & 7,9 & 1,12 & 63.960 & 6,3 & 1.15 \\
\hline Mat. elétrico/comunic. & 153.980 & 9,9 & 1,22 & 57.940 & 5,7 & 1,16 \\
\hline Calçados & 11.600 & 0,7 & 0,27 & 4.240 & 0,4 & 0,17 \\
\hline Mecânica & 129.340 & 8,3 & 0,94 & 86.720 & 8,5 & 0,99 \\
\hline Metal. cirúrgica & 218.720 & 14,0 & 1,14 & 131.940 & 12,9 & 1,12 \\
\hline Química & 192.020 & 12,3 & 1,19 & 184.040 & 18,0 & 1,30 \\
\hline Téxtil & 226.660 & 14,5 & 1,00 & 125.580 & 12,3 & $1 ; 03$ \\
\hline Madeira e mobiliário & 50.380 & 3,2 & 0,84 & 25.920 & 2,5 & 0,73 \\
\hline Mat. de transporte & 212.500 & 13,6 & 1,14 & 117.420 & 11,5 & 1.07 \\
\hline Minerais não metálicos & 54.320 & 3,5 & 0,78 & 26.680 & 2,6 & 0,63 \\
\hline Papel e gráfica & 103.680 & 6,7 & 1,19 & 90.420 & 8.9 & 1,34 \\
\hline Total & 1.557 .920 & 100,0 & 1,00 & 1.021 .000 & 100,0 & 1,00 \\
\hline
\end{tabular}

Fonte: Rais/MTE. Elaboracäo própria. 
22 Inclusive o município de São Paulo, a partir de 2001 (Torres-Freire, Abdal e Bessa, 2010).

${ }^{23}$ Não necessariamente, porém, essa retomada do dinamismo significa novos investimentos. Talvez se deva apenas à recuperação de capacidade ociosa. De uma forma ou de outra, estudos sobre esse tema específico são necessários.
À primeira vista, conclui-se realmente que a RMSP passou por um processo de desconcentração absoluta e relativa - expresso na diminuição do QL e da participação relativa - da indústria. Contudo, uma análise mais cuidadosa permite um entendimento mais adequado do fenômeno. Primeiro, deve-se pontuar que, a partir de 1999, a RMSP reverte as tendências de fechamento de postos de trabalho industriais, ${ }^{22}$ o que significa uma retomada do dinamismo da indústria. ${ }^{23}$ Segundo, nota-se que, no período estudado, do ponto de vista da geração de empregos, o setor de serviços como um todo é bastante mais dinâmico que a indústria, o que se explica pelo impacto diferencial do processo de reestruturação produtiva sobre os diferentes ramos de atividade econômica. Assim, a indústria não deve ser vista como um setor que tende univocamente a abandonar a RMSP; quem tende a fazê-lo são determinados setores industriais que não encontram mais vantagens em ali se localizar. Em outros termos, os setores industriais que ainda encontram vantagens em se localizarem na RMSP - e também no seu entorno, uma vez que gozam das benesses da proximidade à RMSP - são aqueles mais fortemente baseados na ciência, na técnica e no conhecimento.
Ainda em relação à indústria da RMSP, nunca é demais salientar que ela permanece como um dos setores mais importantes em termos de participação relativa, tanto é que chega a 2005 empregando quase um quinto de todos os ocupados na região em questão, o que significa, aproximadamente, um milhão de trabalhadores.

Parte do dinamismo da indústria - não só daquela da RMSP, mas também da indústria das localidades que compõem o seu Campo Aglomerativo -, como argumentado na introdução, é fruto do desempenho extremamente positivo dos serviços produtivos na RMSP, os quais ultrapassam a indústria e o governo em termos de peso relativo, constituindo-se como o ramo que mais emprega na região. Tal fato ganha em significância tanto pela percepção de que os serviços produtivos são apenas o terceiro setor que mais emprega no ESP - atrás dos serviços distributivos e da indústria - quanto pela de que o seu QL, o qual já era o mais alto entre os ramos de atividade da RMSP em 1995, não só se mantém como o mais alto também em 2005, como experimentou relevante tendência de crescimento.

É o bom desempenho dos serviços produtivos que dá força ao argumen- 
to de que a RMSP, ao longo do período aqui analisado, assumiu novas funções, as quais podem ser pensadas de forma análoga às funções de uma cidade global - segundo a discussão feita por Sassen (2001, 1998 e 2005). Mais especificamente, São Paulo assumiu as funções de sítio produtor de serviços especializados de apoio à produção e funções de comando e de articulação da economia nacional e, quiçá, da América do Sul. ${ }^{24}$

Entretanto, São Paulo está longe de constituir-se uma cidade da mesma qualidade que Nova Iorque, Londres e Tóquio. Primeiro, porque São Paulo não detém, definitivamente, poder de comando e de articulação da economia global. Segundo, porque São Paulo, sua Região Metropolitana e Macrometropolitana mantêm-se como importantes polos industriais, aliás, como o mais importante polo industrial brasileiro ${ }^{25}$ e que goza da proximidade ao vasto rol de serviços produtivos ofertados por São Paulo. Terceiro e, talvez mais importante, do ponto de vista da divisão internacional do trabalho, São Paulo e o Brasil estão muito mais próximos do polo oposto do observado por Saskia Sassen ao identificar o processo que desencadeou a emergência de Nova Iorque, Londres e Tóquio como cidades globais, a saber: o processo de desconcentração global da atividade produtiva dos países desenvolvidos rumo aos países em desenvolvimento vis-à-vis a concentração das atividades de gerenciamento e comando da economia nas três referidas cidades.

Em relação aos demais ramos de serviços, vale a pena destacar que os três apresentam concentração bastante próxima da média estadual, o que sugere que a RMSP é um lugar como qualquer outro para sua localização. ${ }^{26}$ Os serviços distributivos configuram-se como o segundo mais importante empregador em 2005, na frente, inclusive, da indústria. Por fim, deve-se atentar para o alto QL do governo - segundo maior da região o qual se deve ao fato de a cidade de São

$\begin{array}{ll}{ }^{24} \text { O que é expresso, por } & { }^{26} \text { Nenhuma outra localidade } \\ \text { exemplo, no processo de } & - \text { com exceção dos serviços } \\ \text { concentração do setor } & \text { distributivos, na RMBS, } \\ \text { financeiro em São Paulo } & \text { por conta do Porto de } \\ \text { (Luna, 2004). } & \text { Santos - apresenta grau de } \\ { }^{25} \text { Lembrar que a RMSP não } & \text { concentração significativo } \\ \text { passou por um processo de } & \text { para os serviços distributivos, } \\ \text { desindustrialização tal qual } & \text { sociais e pessoais. Isso } \\ \text { outras metrópoles dos países } & \text { sugere que o espaço é } \\ \text { desenvolvidos. Sobre o debate } & \text { menos relevante para a } \\ \text { da desindustrialização, ver } & \text { localização desses } \\ \text { Comin e Amitrano (2003), } & \text { serviços do que para a } \\ \text { Amitrano (2004), Diniz e } & \text { indústria e para os } \\ \text { Diniz (2004), Torres-Freire, } & \text { serviços produtivos. }\end{array}$


${ }^{27}$ Aliado ao fato de São Paulo ser a sede administrativa do Estado, deve-se considerar que o emprego na administração pública pode estar sobrestimado, uma vez que certos tipos de servidor público estadual, mesmo trabalhando fora da cidade de São Paulo, tendem a ser declarados como "funcionários do Palácio dos Bandeirantes".
Paulo ser também a capital do Estado. ${ }^{27}$ Como se verificará, nenhuma outra localidade do ESP contará com uma concentração de empregos na administração pública acima da média estadual.

Centrando a análise nos setores industriais, mais especificamente (ver Tabela 3), percebe-se que a RMSP mantémse não só como o mais importante polo industrial do ESP, como é também a localidade do Estado que possui o parque industrial mais denso e diversificado. Isso é expresso pelo alto número de setores - sete - com QL maior que um, sem falar no fato de que, dos cinco com concentração menor que a média estadual, dois aumentaram o seu grau de concentração, com um deles - o mecânico - chegando a praticamente equiparar à média estadual. Assim, em ordem de importância, os setores com concentração relativamente elevada na RMSP são: papel e gráfica; químico; material elétrico e de comunicações; borracha, fumo e couro; metalúrgico; material de transporte; têxtil; e mecânico.

Quanto ao peso relativo dos setores em termos ocupacionais, o destaque vai para a relativamente bem distribuída estrutura de emprego, com cinco setores em 2005 - químico, metalúrgico, têxtil, material de transporte e alimentos e be- bidas - com participação acima da casa dos $10 \%$, e mais dois - papel e gráfica e mecânico - na faixa dos $8 \%$. Todos, juntos, são responsáveis por $82,5 \%$ dos empregos industriais da RMSP.

\section{A Região Metropolitana de Campinas}

A RMCam (ver Tabela 4), ao contrário da RMSP, tem na indústria não só a sua maior fonte de empregos, como também o seu maior grau de concentração - o QL da indústria mantém-se elevado ao longo do período, apesar de o peso relativo da indústria ter experimentado queda de cerca de 7 pontos percentuais. Tal queda de participação da indústria tem relação com o processo de reestruturação produtiva, com destaque para o fenômeno chamado de downsiz̨ing - diminuição da população ocupada sem diminuição da produção - que atingiu a indústria do ESP - e a do Brasil - de meados da década de 1980 até o final dos anos 1990.

Entretanto, mais do que discutir a já esperada alta participação e grau de concentração da indústria na RMCam, convém voltar a atenção para o desempenho da indústria articulada à dos serviços produtivos. Primeiro, porque a forma dessa articulação é semelhante para todas as localidades que compõem o Cam- 
Tabela 4_Distribuicäo dos ocupados e

QLs na RMCam por ramo de atividade econômica (1995 e 2005)

\begin{tabular}{|c|c|c|c|c|c|c|}
\hline \multirow{2}{*}{ Atividade } & \multicolumn{3}{|c|}{1995} & \multicolumn{3}{|c|}{2005} \\
\hline & Abs. & $\%$ & QL & Abs. & $\%$ & QL \\
\hline Indústria & 163.800 & 37,1 & 1,37 & 205.940 & 30,2 & 1,39 \\
\hline Construcao civil & 22.520 & 5,1 & 1,12 & 17.940 & 2,6 & 0,77 \\
\hline S. distributivos & 85.980 & 19,5 & 1,04 & 176.080 & 25,8 & 1,12 \\
\hline S. produtivos & 60.420 & 13,7 & 0,84 & 108.220 & 15,9 & 0,85 \\
\hline S. socials & 37.420 & 8,5 & 1,18 & 53.880 & 7,9 & 1,02 \\
\hline S. pessoais & 17.300 & 3,9 & 1,02 & 32.660 & 4,8 & 1,10 \\
\hline Governo & 37.740 & 8,5 & 0,52 & -55.700 & 8,2 & 0,54 \\
\hline Ativ. primárias & 11.300 & 2,6 & 0,57 & 12.940 & 1,9 & 0,52 \\
\hline Outras ativ. & 5.500 & 1,2 & 0,79 & 17.820 & 2,6 & 1,17 \\
\hline Total & 441.980 & 100,0 & 1,00 & 681.180 & 100,0 & 1,00 \\
\hline
\end{tabular}

Fonte: Rais/MTE. Elaboração própria.

po Aglomerativo da RMSP, com exceção da RMBS. Depois, porque a explicação para o referido padrão da indústria - relativamente mais concentrada no Campo Aglomerativo da RMSP do que na própria RMSP - e dos serviços produtivos - relativamente mais concentrados na RMSP - é comum às seguintes regiões: RMCam, Resto da RAC, RASJC e RASor.

Assim, enquanto a indústria apresenta concentração acima da média estadual, os serviços produtivos contam com concentração abaixo dessa média - no caso da RMCam, o grau de concentração dos serviços produtivos é o mais alto das localidades pertencentes ao Campo
Aglomerativo da RMSP, com exceção da RMBS, o que sugere algumas particularidades. Isso, porém, não significa que a sua indústria não dependa de serviços produtivos, mas apenas que tal indústria se sirva dos serviços produtivos produzidos na RMSP. Nesse sentido, o que se verifica é uma dinâmica na qual a localização na RMCam - ou melhor, no Campo Aglomerativo da RMSP - não implica não acesso às vantagens aglomerativas da RMSP, com grande destaque para os serviços produtivos, principalmente aqueles de caráter mais moderno.

De qualquer forma, o relativamente alto QL dos serviços produtivos 
- em comparação ao de outras localidades do Campo Aglomerativo da RMSP, com exceção da RMBS - sugere que a RMCam possa ser ofertante de certos serviços produtivos - mais rotineiros ou não - complementares e/ou alternativos à RMSP.

Voltando à estrutura produtiva da RMCam, deve-se notar ainda que os demais ramos de serviços mantêm graus de concentração bastante próximos à média estadual, e que os serviços distributivos constituem-se como o segundo ramo que mais emprega na região, atrás apenas da indústria.
Em relação à dinâmica dos setores industriais (Tabela 5), percebe-se que a estrutura industrial da RMCam tendeu à diversificação setorial, o que é expresso no aumento do número de setores com QL maior que um, atingindo a seis em 2005, e perdendo somente para a RMSP. Assim, a RMCam chega a 2005 com os setores têxtil, de material elétrico e de comunicações, de material de transporte, de minerais não metálicos, mecânico e químico com concentração acima da média estadual. Em relação a 1985, a principal alteração foi o crescimento da concentração das indústrias de material

Tahela 5_Distribuição dos ocupados e QLs na RMCam por setor industrial (1985 e 2005)

\begin{tabular}{|c|c|c|c|c|c|c|}
\hline \multirow{2}{*}{ Setor industrial } & \multicolumn{3}{|c|}{1985} & \multicolumn{3}{|c|}{2005} \\
\hline & Abs. & $\%$ & QL & Abs. & $\%$ & QL \\
\hline Alimentos e bebidas & 10.540 & 6,0 & 0,59 & 20.100 & 9,5 & 0,58 \\
\hline Borracha, fumo e couro & 12.860 & 7.3 & 1,04 & 6.600 & 3,1 & 0,57 \\
\hline Mat. elétrico/comunic. & 17.760 & 10,1 & 1,25 & 13.780 & 6,5 & 1,33 \\
\hline Calçados & 1.460 & 0,8 & 0,30 & 420 & 0,2 & 0.08 \\
\hline Mecânica & 16.880 & 9,6 & 1,09 & 20.640 & 9,7 & 1,13 \\
\hline Metal. cirúrgica & 12.660 & 7,2 & 0,59 & 21.080 & 10,0 & 0,86 \\
\hline Química & 17.220 & 9,8 & 0,95 & 32.700 & 15,4 & 1,12 \\
\hline Tëxtil & 45.500 & 25,9 & 1,78 & 41.060 & 19,4 & 1,62 \\
\hline Madeira e mobiliário & 6.760 & 3,9 & 1,00 & 5.360 & 2,5 & 0,73 \\
\hline Mat. de transporte & 19.380 & 11,0 & 0,92 & 29.760 & 14,1 & 1,31 \\
\hline Minerals não metálicos & 9.360 & 5,3 & 1,19 & 10.820 & 5,1 & 1,23 \\
\hline Papel e gráfica & 5.200 & 3,0 & 0,53 & 9.380 & 4,4 & 0,67 \\
\hline Total & 175.580 & 100,0 & 1,00 & 211.700 & 100,0 & 1,00 \\
\hline
\end{tabular}

Fonte: Rais/MTE. Elaboração própria. 
de transporte e química em face da diminuição das de borracha, fumo e couro e de madeira e mobiliário.

Quanto aos setores que mais empregam, destaca-se o têxtil, que, embora tenha diminuído seu peso relativo e fechado postos de trabalho, permaneceu como o setor com maior participação na estrutura ocupacional da RMCam. Deve-se chamar a atenção também para o crescimento das indústrias química, de material de transporte, metalúrgica e de alimentos e bebidas, que, ao lado da indústria mecânica, representam $78,1 \%$ do emprego industrial em 2005.

\section{O Resto da Região Administrativa de Campinas}

A dinâmica da indústria e dos serviços produtivos no Resto da RAC (Tabela 6) é relativamente semelhante à da RMCam, no sentido de a indústria apresentar alto grau de concentração, e os serviços produtivos, baixo grau. A diferença entre as duas localidades, por sua vez, consiste no fato de o grau de concentração da indústria, em 2005, bem como a magnitude de sua expansão entre 1995 e 2005, no Resto da RAC ter sido maior; e no movimento dos serviços produtivos do Resto da RAC ter sido de queda, enquanto a RMCam se manteve estável. De qualquer forma, a mesma explicação fornecida para a RMCam é válida para o Resto da RAC. ${ }^{28}$

Mais dois pontos devem ser notados em relação ao Resto da RAC. O primeiro é o QL dos demais ramos de serviços ser próximo a um, com destaque para os serviços distributivos, que se constituem como o segundo maior empregador da região. Já o segundo ponto diz respeito ao alto grau de concentração das atividades primárias, significativamente mais alto que o QL das atividades primárias da RMCam.

A estrutura setorial da indústria do Resto da RAC, do ponto de vista de seu grau de concentração, tende à especialização produtiva no segmento de minerais não metálicos. Como pode ser observado na Tabela 7 , essa indústria foi a única das que possuíam QL maior que um em 1985, o que ampliou o seu grau de concentração em 2005. Deve-se notar também o crescimento da concentração nos setores de metalurgia, de material de transportes e de material elétrico e de comunicação; o primeiro chega a ultrapassar a média estadual ao passo que os dois últimos dela se aproximam. Tal crescimento, porém, não nos permite ainda falar em concentração significativa nesses setores.

\footnotetext{
${ }_{28}$ Como é válida também para as localidades de RASJC e de RASor. Assim, não será repetida aqui nem nas respectivas análises dessas regiões, desenvolvidas a seguir.
} 
Tabela 6_Distribuição dos ocupados e

QLs no Resto RAC por ramo de atividade econômica (1995 e 2005)

\begin{tabular}{|c|c|c|c|c|c|c|}
\hline \multirow{2}{*}{ Atividade } & \multicolumn{3}{|c|}{1995} & \multicolumn{3}{|c|}{2005} \\
\hline & Abs. & $\%$ & QL & Abs. & $\%$ & QL \\
\hline Indústria & 200.620 & 36,9 & 1,36 & 245.920 & 31,7 & 1,45 \\
\hline Construcão civil & 18.100 & 3,3 & 0,73 & 32.860 & 4,2 & 1,24 \\
\hline S. distributivos & 94.160 & 17,3 & 0,93 & 182.880 & 23,5 & 1,02 \\
\hline S. produtivos & 68.040 & 12,5 & 0,77 & 91.860 & 11,8 & 0,63 \\
\hline S. sociais & 38.420 & 7,1 & 0,98 & 54.860 & 7,1 & 0,91 \\
\hline S. pessoais & 17.640 & 3,2 & 0,85 & 27.220 & 3,5 & 0,81 \\
\hline Governo & 48.240 & 8,9 & 0,54 & 71.040 & 9,1 & 0,61 \\
\hline Ativ. primárias & 52.620 & 9,7 & 2,15 & 53.960 & 6,9 & 1,90 \\
\hline Outras ativ. & 6.300 & 1,2 & 0,73 & 16.000 & 2,1 & 0,92 \\
\hline Total & 544.140 & 100,0 & 1,00 & 776.600 & 100,0 & 1,00 \\
\hline
\end{tabular}

Fonte: Rais/MTE. Elaboração própria.

Tabela 7_Distribuição dos ocupados e QLs no Resto da RAC por setor industrial (1985 e 2005)

\begin{tabular}{|c|c|c|c|c|c|c|}
\hline \multirow{2}{*}{ Setor industrial } & \multicolumn{3}{|c|}{1995} & \multicolumn{3}{|c|}{2005} \\
\hline & Abs. & $\%$ & $\mathbf{Q L}$ & Abs. & $\%$ & QL \\
\hline Alimentos e bebidas & 36.360 & 18,8 & 1,84 & 41.980 & 17,0 & 1,04 \\
\hline Borracha, fumo e couro & 7.800 & 4,0 & 0,57 & 8.700 & 3,5 & 0,65 \\
\hline Mat. eletrico/comunic. & 5.420 & 2,8 & 0,35 & 9.260 & 3,7 & 0,77 \\
\hline Calçados & 8.400 & 4,3 & 1,58 & 460 & 0,2 & 0,08 \\
\hline Mecânica & 24.660 & 12,7 & 1,45 & 26.480 & 10,7 & 1,25 \\
\hline Metalúrgica & 23.100 & 11,9 & 0,97 & 32.940 & 13,3 & 1,15 \\
\hline Química & 11.120 & 5,7 & 0,55 & 28.400 & 11,5 & 0,83 \\
\hline Têxtil & 23.380 & 12,1 & 0,83 & 25.520 & 10,3 & 0,86 \\
\hline Madeira e mobiliário & 8.800 & 4,5 & 1,19 & 9.020 & 3,6 & 1,05 \\
\hline Mat. de transporte & 13.520 & 7,0 & 0,59 & 24.640 & 10,0 & 0,93 \\
\hline Minerais não metálicos & 17.380 & 9,0 & 2,00 & 23.920 & 9,7 & 2,34 \\
\hline Papel e gráfica & 13.640 & 7,0 & 1,26 & 15.900 & 6,4 & 0,97 \\
\hline Total & 193.580 & 100,0 & 1,00 & 247.220 & 100,0 & 1,00 \\
\hline
\end{tabular}

Fonte: Rais/MTE. Elaboracào própria. 
Ainda em relação ao QL, a trajetória dos setores de alimentos e bebidas e de calçados sugere um movimento de desconcentração dessas indústrias no Resto da RAC. Enquanto o setor de alimentos e bebidas embarca em um movimento de desconcentração relativa - diminuição do grau de concentração, em comparação à concentração do setor no ESP, todavia não acompanhada por diminuição da participação do setor na localidade -, a indústria de calçados entra em ciclo de desconcentração relativa e absoluta. Esse é expresso pela diminuição do QL acompanhado pela significativa diminuição de seu peso relativo na localidade.

Quanto à participação dos setores industriais no emprego total, pode-se afirmar que a ocupação é relativamente bem distribuída. Em 2005, havia seis setores com peso relativo acima dos $10 \%-$ alimentos e bebidas, metalurgia, química, mecânica, têxtil e material de transporte - e um muito próximo a $10 \%$ - minerais não metálicos. Juntos, empregavam $82,5 \%$ dos empregados industriais do Resto da RAC.

A comparação entre a estrutura produtiva da RMCam e a do Resto da RAC evidencia que a decisão de separar a Região Administrativa de Campinas em du- as localidades foi acertada. Em relação à estrutura produtiva, de forma mais geral, algumas diferenças podem ser listadas: (i) apesar do alto grau de concentração da indústria em ambas as regiões, a composição interna das respectivas indústrias é bastante diferente; (ii) a performance dos serviços produtivos também é marcada por movimentos distintos; e (iii) a importância das atividades primárias para o Resto da RAC configura-se como mais um ponto de diferenciação.

No que diz respeito às respectivas estruturas setoriais da indústria, é necessário tecer um comentário um pouco mais aprofundado - uma vez que, além de ser bastante diferentes, se encontram em trajetórias com sentidos distintos. Enquanto a estrutura produtiva na RMCam é mais estável, no sentido de ter tido menor variação em termos de níveis setoriais de concentração espacial, não apresentando especialização produtiva explícita em nenhum setor, mas apenas grau de concentração maior que a média estadual em seis setores, no Resto da RAC a estrutura produtiva está em processo de transição, ou seja, contém movimentos significativos de ascensão e queda dos níveis de concentração setorial. Assim, a estrutura produtiva desta última, em 2005, é radicalmente diferen- 
te da que exibia em 1985, especialmente pelo fato de ter se especializado na indústria de minerais não metálicos, nesses últimos 20 anos.

\section{A Região Administrativa de São José dos Campos}

Tal qual verificado para a RMCam e para o Resto da RAC, a RASJC (ver Tabela 8) também apresenta uma relativamente alta concentração da indústria - principalmente quando comparada à RMSP - e baixa concentração do ramo de serviços produtivos. Contudo, aqui, a concentração da indústria não é tão elevada como nas duas localidades anteriores, nem a dos serviços produtivos é tão bai- xa como a do Resto da RAC e da RASor - que será apresentada na próxima seção. Em relação aos serviços produtivos, o seu dinamismo, em termos de grau de concentração e de participação relativa, sugere que a localidade em questão possa vir a se constituir como um polo secundário de fornecimento de serviços produtivos, ao lado da RMCam. Outra possibilidade, mais realista e que não está em oposição à última, é a possibilidade de os serviços produtivos na RASJC possuírem forte ligação com a indústria de material de transporte - mais especificamente, com a aeronáutica -, que, como se verá adiante, é fortemente concentrada na região.

Tabela 8_ Distribuição dos ocupados e

QLs na RASJC por ramo de atividade econômica (1995 e 2005)

\begin{tabular}{|c|c|c|c|c|c|c|}
\hline \multirow{2}{*}{ Atividade } & \multicolumn{3}{|c|}{1995} & \multicolumn{3}{|c|}{2005} \\
\hline & Abs. & $\%$ & QL & Abs. & $\%$ & QL \\
\hline Indústria & 89.920 & 31,9 & 1,18 & 100.420 & 24,8 & 1,14 \\
\hline Construção civil & 11.100 & 3,9 & 0,87 & 12.220 & 3,0 & 0,89 \\
\hline S. distributivos & 56.860 & 20,2 & 1,08 & 95.580 & 23,6 & 1,02 \\
\hline S. produtivos & 32.980 & 11,7 & 0,72 & 62.160 & 15,4 & 0,82 \\
\hline S. sociais & 24.920 & 8,9 & 1,23 & 33.020 & 8,2 & 1,05 \\
\hline S. pessoais & 13.260 & 4,7 & 1,23 & 24.460 & 6,0 & 1,39 \\
\hline Governo & 36.380 & 12,9 & 0,79 & 54.300 & 13,4 & 0,89 \\
\hline Ativ. primárias & 11.240 & 4,0 & 0,89 & 11.760 & 2,9 & 0,79 \\
\hline Outras ativ. & 4.900 & 1,7 & 1,10 & 10.680 & 2,6 & 1,18 \\
\hline Total & 281.560 & 100,0 & 1,00 & 404.600 & 100,0 & 1,00 \\
\hline
\end{tabular}

Fonte. Rais/MTE. Elaboração própria 
Quanto aos demais ramos de serviços, nota-se que todos apresentam concentração próxima às médias estaduais, com exceção dos serviços pessoais - porém, o relativamente alto QL dos serviços pessoais não se reflete em elevado nível de emprego. Além disso, os serviços distributivos são bastante relevantes do ponto de vista do emprego, chegando, em 2005, a praticamente empatar com a indústria.

Com relação à composição setorial da indústria na RASJC (Tabela 9), observa-se que a localidade se caracteri- za pela alta especialização produtiva no setor de material de transporte, ${ }^{29}$ a qual tendeu a se ampliar entre 1985 e 2005. Além da expressiva concentração nesse setor, apenas as indústrias de material elétrico e de comunicação, de química e de metalurgia contam com grau de concentração ligeiramente acima da média. Todos os demais setores industriais apresentam grau de concentração significativamente abaixo do todo do ESP.

O setor de material de transporte, sozinho, é responsável por um terço das ocupações industriais da RASJC. Com

Tabela 9_Distribuição dos ocupados e QLs na RASJC por setor industrial (1985 e 2005)

\begin{tabular}{|c|c|c|c|c|c|c|}
\hline \multirow{2}{*}{ Setor industrial } & \multicolumn{3}{|c|}{1995} & \multicolumn{3}{|c|}{2005} \\
\hline & Abs. & $\%$ & $\mathbf{Q L}$ & Abs. & $\%$ & QL \\
\hline Alimentos e bebidas & 3.940 & 3,6 & 0,35 & 8.120 & 7,9 & 0,49 \\
\hline Borracha, fumo e couro & 9.940 & 9,0 & 1,28 & 2.420 & 2,4 & 0,43 \\
\hline Mat. elétrico/comunic. & 11.700 & 10,6 & 1,31 & 6.160 & 6,0 & 1,23 \\
\hline Calçados & 2.160 & 2,0 & 0,71 & 20 & 0,0 & 0,01 \\
\hline Mecânica & 5.160 & 4,7 & 0,53 & 7.980 & 7,8 & 0,91 \\
\hline Metalúrgica & 11.540 & 10,4 & 0,85 & 12.200 & 11,9 & 1,03 \\
\hline Química & 11.380 & 10,3 & 0.99 & 14.460 & 14,1 & 1.02 \\
\hline Têxtil & 9.220 & 8,3 & 0,57 & 5.000 & 4,9 & 0,41 \\
\hline Madeira e mobiliário & 1.240 & 1,1 & 0,29 & 2.020 & 2,0 & 0,57 \\
\hline Mat. de transporte & 36.740 & 33,2 & 2,78 & 37.160 & 36,2 & 3,37 \\
\hline Minerais não metálicos & 3.560 & 3,2 & 0,72 & 3.300 & 3,2 & 0,78 \\
\hline Papel e gráfica & 4.100 & 3,7 & 0,66 & 3.700 & 3,6 & 0,55 \\
\hline Total & 110.680 & 100,0 & 1,00 & 102.540 & 100,0 & 1,00 \\
\hline
\end{tabular}

Fonte: Rais/MTE. Elaboracão própria

\footnotetext{
29 Com grande destaque para a indústria aeronáutica, a qual conta com elevada concentração na RASJC. Além de a Embraer manter a sua sede, o centro de P\&D e a unidade produtiva de aviões comerciais na localidade, alguns de seus principais fornecedores tamvebém nela se localizam. A respeito da indústria aeronáutica no ESP, ver Ferreira (2008), e da Embraer, mais especificamente, ver Miranda (2007).
} 
peso relativo acima da casa dos $10 \%$, há apenas os setores de química e metalurgia; todos os demais não chegam a $8 \%$. Nesse sentido, pode-se afirmar que a especialização em material de transporte na RASJC é tão forte que fez convergir, até mesmo, a sua estrutura de emprego.

\section{A Região Administrativa de Sorocaba}

A estrutura produtiva da RASor é relativamente semelhante à do Resto da RAC (Tabela 10). Enquanto a indústria conta com alto grau de participação, ampliado no período, os serviços produtivos trilharam o caminho inverso. O seu QL, que já não era tão alto em 1995, tendeu a diminuir ainda mais em 2005.

Outro ponto de comparação são os relativamente elevados peso e grau de concentração das atividades primárias. Já em relação aos demais ramos de serviços, via de regra, esses tendem a ter concentração próxima à média estadual.

A estrutura setorial da indústria da RASor pode ser considerada como em meio a um processo de transição (Tabela 11). Tal processo se caracteriza pela desconcentração relativa de setores que tradicionalmente gozavam de alto grau de concentração, como o de mine- rais não metálicos e o têxtil, e pela elevação do grau de concentração de setores que há 20 anos não figuravam entre aqueles com maior concentração na RASor, como os de material de transporte, de material elétrico e de comunicações e de madeira e mobiliário. Em relação ao último, o seu significativo crescimento sugere o início de uma trajetória de especialização produtiva.

Quando se olha para os setores que mais empregam, verifica-se que os que mais ampliaram o seu grau de concentração não foram aqueles com maior peso relativo. A indústria com maior participação no emprego é a de alimentos e bebidas, cujo grau de concentração se manteve relativamente estável e próximo à média estadual. A essa, segue-se a têxtil, que passou por processo de desconcentração relativo; e a metalúrgica, que se encontra em situação semelhante à de alimentos e bebidas. $\mathrm{O}$ único setor que ampliou seu grau de concentração de forma significativa e que conta com peso relativo acima de $10 \%$ é o de material de transporte. Esses quatro setores, mais o químico, que apresenta participação bastante próxima à casa dos 10\%, são responsáveis por $63,5 \%$ dos empregos industriais da RASor. 
Tabela 10_ Distribuicão dos ocupados e

QLs na RASOr por ramo de atividade econômica (1995 e 2005)

\begin{tabular}{|c|c|c|c|c|c|c|}
\hline \multirow{2}{*}{ Atividade } & \multicolumn{3}{|c|}{1995} & \multicolumn{3}{|c|}{2005} \\
\hline & Abs. & $\%$ & QL & Abs. & $\%$ & QL \\
\hline Indústria & 1.19 .660 & 32,5 & 1,20 & 154.060 & 29,5 & 1,36 \\
\hline Construção civil & 10.240 & 2,8 & 0,61 & 17.960 & 3,4 & 1,01 \\
\hline S. distributivos & 65.120 & 17,7 & 0,95 & 114.300 & 21,9 & 0,95 \\
\hline S. produtivos & 50.860 & 13,8 & 0,85 & 55.040 & 10,5 & 0,56 \\
\hline S. sociais & 23.300 & 6,3 & 0,88 & 29.220 & 5,6 & 0,72 \\
\hline S. pessoais & 12.600 & 3,4 & 0,89 & 22.640 & 4,3 & 1,00 \\
\hline Governo & 39.920 & 10,8 & 0,66 & 60.960 & 11,7 & 0,78 \\
\hline Atv. primárias & 40.640 & 11,0 & 2,46 & 55.920 & 10,7 & 2,93 \\
\hline Outras atv. & 5.640 & 1,5 & 0,97 & 11.820 & 2,3 & 1,02 \\
\hline Total & 367.980 & 100,0 & 1,00 & 521.920 & 100,0 & 1.00 \\
\hline
\end{tabular}

Fonte: Rais/MTE. Elaboração própria.

Tabela 11_Distribuicäo dos ocupados e QLs na RASor por setor industrial (1985 e 2005)

\begin{tabular}{|c|c|c|c|c|c|c|}
\hline \multirow{2}{*}{ Setor industrial } & \multicolumn{3}{|c|}{1995} & \multicolumn{3}{|c|}{2005} \\
\hline & Abs. & $\%$ & QL & Abs. & $\%$ & QL \\
\hline Alimentos e bebidas & 11.660 & 9,2 & 0,90 & 25.060 & 15,8 & 0,97 \\
\hline Borracha, fumo e couro & 4.360 & 3,4 & 0,49 & 6.980 & 4,4 & 0,81 \\
\hline Mat. eletrico/comunic. & 8.940 & 7,1 & 0,87 & 9.480 & 6,0 & 1,22 \\
\hline Calçados & 2.080 & 1,6 & 0,60 & 60 & 0,0 & 0,02 \\
\hline Mecânica & 10.680 & 8,4 & 0,96 & 13.320 & 8,4 & 0,98 \\
\hline Metalúrgica & 16.780 & 13,3 & 1,08 & 20.420 & 12,9 & 1,11 \\
\hline Química & 5.780 & 4,6 & 0,44 & 15.020 & 9,5 & 0,68 \\
\hline Têxtil & 32.140 & 25,4 & 1,74 & 23.580 & 14,8 & 1,24 \\
\hline Madeira e mobiliário & 7.640 & 6,0 & 1,57 & 10.820 & 6,8 & 1,97 \\
\hline Mat. de transporte & 10.060 & 7,9 & 0,67 & 16.780 & 10,6 & 0,98 \\
\hline Minerais não metálicos & 12.440 & 9,8 & 2,19 & 11.080 & 7,0 & 1,68 \\
\hline Papel e gráfica & 4.000 & 3,2 & 0,56 & 6.240 & 3,9 & 0,59 \\
\hline Total & 126.560 & 100,0 & 1,00 & 158.840 & 100,0 & 1,00 \\
\hline
\end{tabular}

Fonte: Rais/MTE. Elaboração própria. 
30 Santos tem o maior porto da América Latina e o mais importante porto brasileiro, com sua área de influência englobando as regiões Sul, Sudeste, Centro-Oeste e parte do Nordeste (Neto, 2009).

\section{A Região Metropolitana da Baixada Santista}

Como pode ser observado na Tabela 12, a RMBS apresenta estrutura produtiva bastante discrepante das apresentadas pelas demais localidades do Campo Aglomerativo da RMSP. É possível que grande parte dessas diferenças seja explicada pela sua vocação para o desenvolvimento de serviços distributivos - especialmente daqueles relacionados às atividades portuárias ${ }^{30}$ - devido a sua localização litorânea e a sua proximidade à região mais desenvolvida da nação. Assim, a RMBS é a única localidade do ESP que apresenta especialização em tal ramo de atividade econômica.

Convém atentar para o fato de que os serviços produtivos também contam com alto grau de concentração na RMBS, superior ao de todas as demais localidades do Campo Aglomerativo da RMSP. Entretanto, tudo indica que tais serviços possuam mais ligação com as atividades portuárias do que com a indústria. Por fim, serviços sociais e pessoais também têm QL acima de um, com destaque para os pessoais, cujo QL é elevado e aumenta no período em questão.

Em relação à indústria, o que salta aos olhos é o baixo grau de concentração e a baixa participação na estrutura do em- prego, ambos declinantes ao longo do período. Nesse sentido, é possível falar que a indústria da RMBS passa por um processo de desconcentração absoluta e relativa. De qualquer forma, observa-se (Tabela 13) que a RMBS apresenta estrutura setorial da indústria bastante concentrada em alguns poucos setores, visível tanto quando se compara a concentração desses com a média estadual quanto quando se focaliza a estrutura do emprego.

O setor de metalurgia apresenta alto grau de concentração - o que sugere uma especialização da RMBS -, ao passo que os setores de química e de alimentos e bebidas contam com uma concentração relativamente maior que a média estadual. Em relação aos dois últimos, cabe chamar a atenção para a sua dinâmica diferenciada. Enquanto o de alimentos e bebidas apresenta um movimento de ampliação de seu grau de concentração, o químico mostra um movimento de desconcentração absoluta e relativa, o que abre a possibilidade de, num futuro próximo, deixar de ser um dos setores da RMBS com grau de concentração acima da média estadual.

Muito em decorrência do referido alto grau de concentração, os setores de metalurgia, alimentos e bebidas e o químico são responsáveis por $61,2 \%$ dos empre- 
Tabela 12 _ Distribuição dos ocupados e

QLs na RMBS por ramo de atividade econômica (1995 e 2005)

\begin{tabular}{|c|c|c|c|c|c|c|}
\hline \multirow{2}{*}{ Atividade } & \multicolumn{3}{|c|}{1995} & \multicolumn{3}{|c|}{2005} \\
\hline & Abs. & $\%$ & QL & Abs. & $\%$ & QL \\
\hline Indústria & 25.580 & 10,8 & 0,40 & 19.880 & 6,9 & 0,32 \\
\hline Construcão civil & 17.260 & 7,3 & 1,61 & 14.640 & 5,1 & 1,49 \\
\hline S. distributivos & 64.340 & 27,2 & 1,46 & 90.980 & 31,6 & 1,37 \\
\hline S. produtivos & 49.140 & 20,8 & 1,28 & 60.120 & 20,9 & 1,12 \\
\hline S. sociais & 19.260 & 8,2 & 1,14 & 23.980 & 8,3 & 1,07 \\
\hline S. pessoais & 12.340 & 5,2 & 1,36 & 18.120 & 6,3 & 1,45 \\
\hline Governo & 24.640 & 10,4 & 0,64 & 37.700 & 13,1 & 0,87 \\
\hline Ativ. primárias & 3.260 & 1,4 & 0,31 & 1.720 & 0,6 & 0,16 \\
\hline Outras ativ. & 20.440 & 8,7 & 5,49 & 21.200 & 7,4 & 3,30 \\
\hline Total & 236.260 & 100,0 & 1,00 & 288.340 & 100,0 & 1,00 \\
\hline
\end{tabular}

Fonte: Rais/MTE. Elaboração própria.

Tabela 13_Distribuição dos ocupados e QLs na RMBS por setor industrial (1985 e 2005)

\begin{tabular}{|c|c|c|c|c|c|c|}
\hline \multirow{2}{*}{ Setor industrial } & \multicolumn{3}{|c|}{1985} & \multicolumn{3}{|c|}{2005} \\
\hline & Abs. & $\%$ & QL & Abs. & $\%$ & QL \\
\hline Alimentos e bebidas & 3.700 & 9,9 & 0,97 & 4.880 & 22,3 & 1,37 \\
\hline Borracha, fumo e couro & 1.700 & 4,5 & 0,64 & 360 & 1,6 & 0,30 \\
\hline Mat. elétricos/comunic. & 240 & 0,6 & 0,08 & 20 & 0,1 & 0,02 \\
\hline Calçados & 420 & 1,1 & 0,41 & 0 & 0,0 & 0,00 \\
\hline Mecânica & 440 & 1,2 & 0,13 & 1.460 & 6,7 & 0,78 \\
\hline Metalúrgica & 14.180 & 37,9 & 3,08 & 7.060 & 32,2 & 2,79 \\
\hline Química & 10.320 & 27,6 & 2,66 & 4.180 & 19,1 & 1,38 \\
\hline Têxtil & 1.460 & 3,9 & 0,27 & 1.460 & 6,7 & 0,56 \\
\hline Madeira e mobiliário & 640 & 1,7 & 0,45 & 260 & 1,2 & 0,34 \\
\hline Mat. de transporte & 1.400 & 3,7 & 0,31 & 280 & 1,3 & 0,12 \\
\hline Minerais não metálicos & 1.260 & 3,4 & 0,75 & 580 & 2,6 & 0,64 \\
\hline Papel e gráfica & 1.680 & 4,5 & 0,80 & 1.360 & 6,2 & 0,94 \\
\hline Total & 37.440 & 100,0 & 1,00 & 21.900 & 100,0 & 1,00 \\
\hline
\end{tabular}

Fonte: Rais/MTE. Elaboração própria. 
31 Uma investigação mais pormenorizada desse possível processo recente de industrialização do interior do Estado requer, entre outras coisas, maior desagregação do que aqui se chamou "Outras RAs”. Embora relevante, tal investigação não será feita aqui.

32 Ainda que a indústria de alimentos e bebidas tenha diminuído o seu grau de concentração nas Outras RAs do ESP, o que sugere um processo de desconcentração relativa. gos industriais da RMBS. O quarto setor que mais emprega é o têxtil, que conta com peso relativo de apenas $6,7 \%$.

\section{As demais Regióes Administrativas do Estado de São Paulo}

$\mathrm{Na}$ Tabela 14, observa-se a distribuição dos ocupados e dos QLs nas Outras RAs do ESP para os anos 1995 e 2005. Para começar, deve-se notar a significativa tendência de aumento do grau da concentração da indústria, a qual se situava abaixo da média estadual em 1995 e tornou-se superior a essa média em 2005 - com o QL, por exemplo, semelhante ao da RASJC. Esse movimento sugere que as Outras RAs do ESP estejam experimentando um processo de industrialização. ${ }^{31}$

No que diz respeito aos serviços, nota-se que, com exceção dos serviços produtivos, os demais ramos tendem a ter grau de concentração próximo à média estadual. Os serviços produtivos, por sua vez, apresentaram diminuição no seu já baixo grau de concentração e na sua participação relativa - apesar de terem experimentado aumento, é verdade que menos que proporcional do que o aumento dos outros ramos de atividades econômicas, de seu contingente de trabalhadores.

Por fim, deve-se salientar o grande peso e grau de concentração das ativi- dades primárias nas Outras RAs do ESP. Como é sabido, a agricultura paulista, que se caracteriza por ser bastante moderna e dinâmica, está, majoritariamente, localizada nas Outras RAs do ESP.

Com relação à indústria, agora, a partir da sua composição setorial, percebe-se que as Outras RAs do ESP, de forma análoga à RMBS, contam com estrutura setorial concentrada em poucos setores (Tabela 15): o de calçados, o de alimentos e bebidas, o de madeira e mobiliário e o de borracha, fumo e couro. Destacam-se a enorme concentração da indústria de calçados e a também expressiva concentração de alimentos e bebidas ${ }^{32}$ - aliás, é provável que exista forte ligação entre esta última e as atividades primárias, bastante fortes na localidade. Deve-se notar ainda que os setores de mecânica e de minerais metálicos passaram por processo semelhante, experimentando um movimento que levou seus respectivos graus de concentração abaixo das médias estaduais.

No que concerne à distribuição do emprego, percebe-se que, com exceção dos setores de alimentos e bebidas e calçados, os quais têm peso relativo de, respectivamente, $35,6 \%$ e $11,5 \%$, todos os demais contam com participação inferior a $10 \%$. 
Tabela 14_Distribuicao dos ocupados e

QLs nas Outras RAs por ramo de atividade econôrnica (1995 e 2005)

\begin{tabular}{|c|c|c|c|c|c|c|}
\hline \multirow{2}{*}{ Atividade } & \multicolumn{3}{|c|}{1995} & \multicolumn{3}{|c|}{2005} \\
\hline & Abs. & $\%$ & $\mathbf{Q L}$ & Abs. & $\%$ & $\mathbf{Q L}$ \\
\hline Indústria & 299.780 & 23,8 & 0,88 & 417.460 & 25,2 & 1,16 \\
\hline Construção civil & 43.420 & 3,4 & 0,76 & 44.980 & 2,7 & 0,80 \\
\hline S. distributivos & 227.600 & 18,0 & 0,97 & 398.720 & 24,0 & 1,04 \\
\hline S. produtivos & 126.680 & 10,0 & 0,62 & 151.860 & 9,2 & 0,49 \\
\hline S. sociais & 97.960 & 7,8 & 1,08 & 136.320 & 8,2 & 1,06 \\
\hline S. pessoais & 32.280 & 2,6 & 0,67 & 57.000 & 3,4 & 0,79 \\
\hline Governo & 212.860 & 16,9 & 1,03 & 205.960 & 12,4 & 0,82 \\
\hline Ativ. primárias & 201.360 & 16,0 & 3,55 & 203.120 & 12,3 & 3,35 \\
\hline Outras ativ. & 19.140 & 1,5 & 0,96 & 42.580 & 2,6 & 1,15 \\
\hline Total & 1.261 .080 & 100,0 & 1,00 & 1.658 .000 & 100,0 & 1,00 \\
\hline
\end{tabular}

Fonte: Rais/MTE. Elaboração própria.

Tabela 15_Distribuicao dos ocupados e QLs nas Outras RAs do ESP por setor industrial (1985 e 2005)

\begin{tabular}{|c|c|c|c|c|c|c|}
\hline \multirow{2}{*}{ Setor industrial } & \multicolumn{3}{|c|}{1995} & \multicolumn{3}{|c|}{2005} \\
\hline & Abs. & $\%$ & QL & Abs. & $\%$ & $\mathbf{Q L}$ \\
\hline Alimentos e bebidas & 107.020 & 35,4 & 3,47 & 149.700 & 35,6 & 2,18 \\
\hline Borracha, fumo e couro & 16.600 & 5,5 & 0,78 & 29.520 & 7,0 & 1,29 \\
\hline Mat. elétricos/comunic. & 4.800 & 1,6 & 0,20 & 10.140 & 2,4 & 0,49 \\
\hline Calçados & 42.460 & 14,0 & 5,12 & 48.480 & 11,5 & 4,69 \\
\hline Mecânica & 33.300 & 11,0 & 1,25 & 31.180 & 7,4 & 0,86 \\
\hline Metalúrgica & 11.500 & 3,8 & 0,31 & 26.520 & 6,3 & 0,55 \\
\hline Química & 11.820 & 3,9 & 0,38 & 23.560 & 5,6 & 0,40 \\
\hline Têxtil & 27.240 & 9,0 & 0,62 & 38.740 & 9,2 & 0,77 \\
\hline Madeira e mobiliário & 20.540 & 6,8 & 1,77 & 22.300 & 5,3 & 1,53 \\
\hline Mat. de transporte & 5.360 & 1,8 & 0,15 & 9.060 & 2,2 & 0,20 \\
\hline Minerais não metálicos & 13.820 & 4,6 & 1,02 & 14.060 & 3,3 & 0,81 \\
\hline Papel e gráfica & 8.120 & 2,7 & 0,48 & 17.360 & 4,1 & 0,62 \\
\hline Total & 302.580 & 100,0 & 1,00 & 420.620 & 100,0 & 1,00 \\
\hline
\end{tabular}

Fonte: Rais/MTE. Elaboração própria. 


\section{Síntese}

A análise precedente visou demonstrar que as localidades do ESP apresentam estruturas produtivas bem diferentes umas das outras, além de caracterizá-las a partir de suas especificidades. De modo geral, podese afirmar que as três regiões do ESP RMSP, Campo Aglomerativo da RMSP e Resto do ESP, sendo o segundo composto das localidades da RMCam, Resto da RAC, RASJC, RASor e RMBS - contam com estruturas produtivas bastante díspares umas das outras, as quais não tendem a convergência. Enquanto a RMSP caracteriza-se por se constituir como o polo de produção de serviços produtivos, especialmente daqueles de caráter mais moderno, mais importante da Nação - quiçá da América do Sul - sem, entretanto, deixar de ser um significativo centro industrial, as localidades que compõem o seu Campo Aglomerativo constituem-se como espaços propícios ao desenvolvimento industrial, cujasempresas auferem as vantagens aglomerativas da RMSP, com destaque para ovasto rol de serviços especializados. Já o Resto do ESP é marcado tanto por uma aparentemente recente e intensa onda de industrialização quanto pela força de sua agricultura, a qual, além de ser a mais moderna e dinâmica do País, mantém forte ligação com a indústria - especialmente com o setor de alimentos e bebidas.
De modo mais específico, agora voltando a atenção para a composição setorial das indústrias das respectivas localidades do ESP, duas considerações podem ser feitas valendo-se da noção de que os espaços metropolitanos são locais qualitativamente diferenciados para a produção.

A primeira é que justamente as duas maiores e mais diversificadas localidades do ESP - RMSP e RMCam - se caracterizam pela diversificação e pela densidade de seu parque industrial, manifestas em uma quantidade relativamente elevada de setores com grau de concentração acima da média do ESP. Portanto, não é possível identificar em nenhuma dessas localidades um movimento unívoco de especialização produtiva em torno de um único setor.

A segunda diz respeito a uma tendência própria das outras cinco localidades do ESP. O Resto da RAC, a RASJC, a RASor, a RMBS e as Outras RAs do ESP se distinguem pela especialização produtiva em um ou dois setores. Aqui, a tendência geral é que tal especialização produtiva se reflita na estrutura de emprego, de modo a fazer com que o setor que apresenta a especialização seja o maior - ou um dos maiores - gerador de empregos industriais da localidade. 


\section{Referências bibliográficas}

ABDAL, Alexandre. Desenvolvimento e espaço: da hierarquia da desconcentração industrial da Região Metropolitana de São Paulo à formação da Macrometrópole Paulista. 2008. 136 f. Dissertação (Mestrado em Sociologia) Faculdade de Filosofia, Letras e Ciências Humanas, Universidade de São Paulo (FFLCH-USP), São Paulo, 2008. Disponível em: <http://www.teses.usp.br/ teses/disponiveis/8/8132/tde04072008-095824/>. Acesso em: 10 de março de 2009.

AMITRANO, Cláudio. A Região Metropolitana e a área central da cidade de São Paulo nos anos 90: estagnação ou adaptação. In: COMIN, Alvaro A.; SOMEKH, Nadia. (coordenação geral). Caminhos para o Centro: estratégias de desenvolvimento para a região central de São Paulo. São Paulo: Convênio Emurb/Cebrap/ Cem, 2004

ARAÚJO, Maria de Fátima I. Reestruturação produtiva e transformações econômicas.

Região Metropolitana de São

Paulo. Revista São Paulo em Perspectiva, São Paulo, v. 15, n. 1, 2001
ARBIX, Glauco. Inovar ou inovar: a indústria brasileira entre o passado e o futuro. São Paulo:

Papagaio, 2007.

\section{AZZONI, Carlos Roberto.}

Indústria e reversão da polariząąão no Brasil. São Paulo:

IPE-USP, 1986.

BERNARDES, Roberto $e t$ al. Serviços na PAEP 2001: reconfigurando a agenda de pesquisas estatísticas de inovação. Revista São Paulo em Perspectiva, São Paulo, v. 19, n. 2, 2005

BESSA, Vagner. O setor de serviços às empresas. In: COMIN, Alvaro A.; SOMEKH, Nadia. (coordenação geral). Caminhos para o centro: estratégias de desenvolvimento para a região central de São Paulo. São Paulo: Convênio Emurb/Cebrap/ Cem, 2004.

BODEN, Mark; MILES, Ian. Services and the knowledge-based economy. London and New York: Continuum, 2000.

CAIADO, Aurílio Sérgio Costa. Desconcentração industrial regional no Brasil (1985-1998): pausa ou retrocesso? 2002. $269 \mathrm{f}$. Tese (Doutorado em Economia) - Instituto de Economia da Unicamp, Campinas, 2002.
CANO, Wilson. Desequilibrios regionais e concentracão industrial no Brasil: 1930-1970 e 1970-1995. Campinas: IE-Unicamp, 1998.

CASTELLS, Manuel. $A$ sociedade em rede. São Paulo: Paz e Terra, 1999.

CASTRO, Antonio Barros de. A reestruturação industrial brasileira nos anos 90: uma interpretação. Revista de Economia e Politica, v. 21, n. 3, p. 83, jul./set. 2001.

COMIN, Álvaro. Mudanças na estrutura ocupacional do mercado de trabalho em São Paulo. 2003. 174 f. Tese (Doutorado em Sociologia) - Faculdade de Filosofia, Letras e Ciências Humanas, Universidade de São Paulo, São Paulo, 2003.

COMIN, Álvaro; AMITRANO, Cláudio. Economia e emprego: a trajetória recente da Região Metropolitana de São Paulo. Novos Estudos Cebrap, São Paulo, n. 66, jul. 2003.

CROCCO, Marco Aurélio et al. Metodologia de identificação de arranjos produtivos locais. Revista Nova Economia, Belo Horizonte, v. 2 , n. 16, maio/ago. 2006.
DINIZ, Célio Campolina.

Desenvolvimento poligonal no Brasil: nem desconcentração, nem contínua polarização. Revista Nova Economia, Belo Horizonte, v. 3 , n. 1,1993

DINIZ, Célio Campolina. Dinâmica regional recente da economia brasileira e suas perspectivas. Brasília: IPEA, 1995. (Texto para discussão, 375).

DINIZ, Célio Campolina. A nova configuração urbano-industrial no Brasil. In: KON, Anita (Org.). Unidade e fragmentação: a questão regional no Brasil. São Paulo: Col. Debates. Editora Perspectiva, 2002.

DINIZ, Célio Campolina; DINIZ, Bernardo Campolina. A Região Metropolitana de São Paulo: reestruturação, re-espacialização e novas funções. In: COMIN, Alvaro A.; SOMEKH, Nadia. (coordenação geral). Caminhos para o centro: estratégias de desenvolvimento para a região central de São Paulo. São Paulo: Convênio Emurb/Cebrap/ Cem, 2004.

DURANTON, Gilles; PUGA, Diego. Diversity and specialisation in cities: why, where and when does it matter? Journal of Planning Literature, v. 15, n. 1, 2000. 
DURANTON, Gilles; PUGA, Diego. Nursery cities: urban diversity, process innovation and the life-cycle of products. CEPR Discussion Paper 2376, to be published in the American Economic Review, 2001.

FERREIRA, Marcos José Barbieri. Discussão da nota técnica do setor de aeronáutica. In: SEMINÁRIO SETORIAL DA AGENDA DA COMPETITIVIDADE DA INDÚSTRIA PAULISTA: $2^{\circ}$ Workshop, IPT/FIPE/FIESP, São Paulo, 2008.

GARCIA, Renato. As economias externas como fonte de vantagens competitivas dos produtores em aglomerações de empresas. In: ENCONTRO NACIONAL DE ECONOMIA POLÍTICA, 7., 2002, Curitiba. Conferências... Curitiba, 2002.

HADDAD, Paulo Roberto. Medidas de localização e de especialização. In: HADDAD, Paulo Roberto et al. Economia regional: teorias e métodos de análise. Fortaleza: Banco do Nordeste, 1989.

HIRSCHMAN, Albert. Grandeza e decadência da economia do desenvolvimento. In: HIRSCHMAN, Albert. A economia como ciência moral e política. São Paulo: Brasiliense, 1986.

JACOBS, Jane. The economy of cities. New York: Vintage Books, 1970.

JACOBS, Jane. Cities and the wealth of nations. Principles of economic life. New York: Random House, 1984
KRUGMAN, Paul. Development, geography and economic theory. Cambridge: MIT Press, 1995.

KUPFER, David; ROCHA, Carlos F. Dinamica da produtividade e beterogeneidade estrutural da indústria brasileira. Santiago de Chile: CEPAL, 2004. (Texto apresentado no seminário: El reto de acelerar el crescimiento em América Latina y el Caribe).

LUNA, Francisco Vidal. A capital financeira do país. In: SZMRECSÁNYI, Tamás (Org.).

História econômica da cidade de São

Paulo. São Paulo: Globo, 2004. (Col. Livros de Valor).

MIRANDA, Zil. O vôo da Embraer: a competitividade brasileira na indústria de alta tecnologia. São Paulo: Papagaio, 2007.

MOULAERT, Frank et al. Producer services and the formation of urban space. In: MOULAERT, Frand; SCOTT, Allen (Eds.). Cities, enterprises and society on the eve of $21^{S T}$ century. London: Wellington House, 1997.

\section{MYRDAL, Gunnar. Teoria} econômica e regiões subdesenvolvidas. Rio de Janeiro: Saga, 1968.

NEGRI, Barjas. Concentração e desconcentração industrial em São Paulo (1880-1990). Campinas: Editora da Unicamp, 1996.

NETO, Carlos Álvares et al. Portos Brasileiros 2009: Ranking, área de influência, porte e valor agregado médio dos produtos movimentados. Rio de Janeiro: IPEA, 2009. (Texto para Discussão, 1408).
PACHECO, Carlos Américo. Fragmentação da nação. Campinas: Instituto de Economia da Unicamp, 1998.

PACHECO, Carlos Américo.

Novos padrões de localização industrial? Tendências recentes dos indicadores da produção e do desenvolvimento industrial. Brasília: IPEA, 1999. (Texto para Discussão, 633).

RODRÍGUEZ-POSE, Andrés; CRESCENZI, Riccardo.

Mountains in a flat word: why proximity still matters for the location of economic activity. Cambridge Journal of Regions, Economy and Society, n. 1, July 2008.

SABÓIA, João. Modernização e redução do tamanho dos estabelecimentos da indústria de transformação no passado recente. In: ENCONTRO NACIONAL DE ECONOMIA DA ANPEC, 25.,1997, Recife. Anais..

Recife, 1997.

SASSEN, Saskia. As cidades na economia mundial. São Paulo: Studio Nobel, 1998.

SASSEN, Saskia. The global city: New York, London, Tokyo. 2nd ed. Princeton: University Press Princeton, 2001.

SASSEN, Saskia. The global city: introducing a concept. The brown journal of world affairs. Volume 6 , issue 2, Winter/Spring, 2005.

SCOTT, Allen J. Geography and economy: three lectures. Oxford: Oxford University Press, 2006.
SCOTT, Allen J.; STORPER, Michael. Regions, globalization, development. Forthcoming In Regional Studies. 2003.

STORPER, Michael. The regional world: territorial development in a global economy. New York: Guiford Press, 1997.

STORPER, Michael; VENABLES, Anthony. Buzz: face-to-face contact and the urban economy. Working paper. London: Centre for Economic Performance - London School of Economics and Political Science, 2003.

SUZIGAN, Wilson et al. Coeficientes de Gini locacionais - GL: aplicação à indústria de calçados do Estado de São Paulo. Revista Nova Economia, Belo Horizonte, v. 3, n. 2 jul./dez. 2003.

TORRES-FREIRE, Carlos. KIBS no Brasil: um estudo sobre os serviços empresariais intensivos em conhecimento na Região Metropolitana de São Paulo. 2006. 181 f. Dissertação (Mestrado em Sociologia) - Faculdade de Filosofia, Letras e Ciências Humanas, Universidade de São Paulo, São Paulo, 2006. Disponível em: <http://www.teses.usp.br/ teses/disponiveis/8/8132/tde12032007-235033/>. Acesso em: 15/03/2009. 
TORRES-FREIRE, Carlos;

ABDAL, Alexandre; BESSA,

Vagner. Conhecimento e

tecnologia: atividades industriais

e de serviços para uma São Paulo

Competitiva. In: COMIN, Álvaro;

TORRES-FREIRE, Carlos;

WISSENBACH, Tomas (Orgs.).

Metamorfoses paulistanas: Atlas

geoeconômico da cidade. São

Paulo: Sempla/Cebrap/Imprensa

Oficial/Editora Unesp, 2010.

No prelo.

VELTZ, Pierre. The dynamics of production systems, territories and cities. In MOULAERT, Frank;

SCOTT, Allen J. (eds). Cities,

enterprises and society on the eve of $21^{\text {s }}$

century. London:

Wellington House, 1997.

Peço licença para agradecer as críticas
e sugestões proferidas pelo men
parecerista à versão anterior
deste artigo.
E-mail de contato do autor:
aleabda@usp.br
Artigo recebido em março de 2009;
aprovado em janeiro de 2010.

